\title{
III-V Gate-all-around Nanowire MOSFET Process Technology: From 3D to 4D
}

\author{
J. J. Gu, ${ }^{1)}$ X. W. Wang, ${ }^{2)}$ J. Shao, ${ }^{3)}$ A. T. Neal, ${ }^{1)}$ M. J. Manfra, ${ }^{3)}$ R. G. Gordon, ${ }^{2)}$ and P. D. Ye ${ }^{1)}$ \\ 1) School of Electrical and Computer Engineering and Birck Nanotechnology Center, Purdue University, West Lafayette, IN 47906, U.S.A. \\ ${ }^{2)}$ Department of Chemistry and Chemical Biology, Harvard University, Cambridge, MA 02138, U.S.A. \\ 3) Department of Physics, Purdue University, West Lafayette, IN, 47906, U.S.A. \\ Tel: 1-765-494-7611, Fax: 1-765-496-7443, Email: yep@purdue.edu, iigu@purdue.edu
}

\begin{abstract}
In this paper, we have experimentally demonstrated, for the first time, III-V 4D transistors with vertically stacked InGaAs nanowire (NW) channels and gate-all-around (GAA) architecture. Novel process technology enabling the transition from $3 \mathrm{D}$ to $4 \mathrm{D}$ structure has been developed and summarized. The successful fabrication of InGaAs lateral and vertical NW arrays has led to $4 \times$ increase in MOSFET drive current. The top-down technology developed in this paper has opened a viable pathway towards future low-power logic and RF transistors with high-density III-V NWs.
\end{abstract}

\section{Introduction}

III-V GAA NWFETs, or III-V 3D transistors, have been experimentally demonstrated by a top-down approach, showing excellent scalability down to channel length $\left(\mathrm{L}_{\mathrm{ch}}\right)$ of $50 \mathrm{~nm}^{[1]}$. However, the $\mathrm{g}_{\mathrm{m}}, \mathrm{SS}$, and DIBL are greatly limited by the large EOT of the devices ${ }^{[1]}$. To improve the electrostatic control, we demonstrate $2 \times$ reduction in EOT while maintaining the low gate leakage in this work. Furthermore, although lateral (parallel to the wafer surface) integration of NWs has been demonstrated with high drive current per wire, the overall current drivability of the devices is still limited by the pitch of the NWs. To overcome the bottleneck of drive current, for the first time, a top-down process technology has been developed to fabricate vertically stacked (normal to the wafer surface) III-V NWFETs, similar to some explored Si NWFETs ${ }^{[2-3]}$. We call this new type of NW devices III-V 4D transistors to distinguish them from IIIV 3D transistors ${ }^{[1]}$ which has only one vertical layer and multiple lateral wires. The experimental results, in this paper, show that the drive current per wire pitch $\left(\mathrm{W}_{\text {pitch }}\right)$ greatly increases from 3D to 4D structure. This new device concept is very promising for future high-speed low-power logic and RF applications.

\section{Experiments}

Fig. 1 shows the diagram of III-V 3D and 4D transistors with $1 \times 2$ and $3 \times 2 \mathrm{NW}$ arrays respectively. Table 1 summarizes the samples investigated in this paper, showing the detailed splits for the NW array, NW size, EOT and the indium content of InGaAs channels. Sample 1 investigates III-V 3D transistors with $5 \mathrm{~nm} \quad \mathrm{Al}_{2} \mathrm{O}_{3} \quad(\mathrm{EOT}=2.2 \mathrm{~nm})$ gate dielectric and $\mathrm{In}_{0.65} \mathrm{Ga}_{0.35} \mathrm{As}$ incorporation in the NWs to increase gate electrostatic control and boost channel mobility, respectively. The fabrication process for III-V 3D transistors has been developed in Ref. [1]. $\mathrm{Al}_{2} \mathrm{O}_{3} / \mathrm{WN}$ high-k/metal gate stack was deposited by atomic layer deposition (ALD). The nanowire width $\left(\mathrm{W}_{\mathrm{NW}}\right)$ is varied from 25 to $35 \mathrm{~nm}$ in $5 \mathrm{~nm}$ steps. Sample
2 demonstrates the first III-V 4D transistors with $10 \mathrm{~nm} \mathrm{Al}_{2} \mathrm{O}_{3}$ $(\mathrm{EOT}=4.5 \mathrm{~nm})$ and $3 \times 2$ or $3 \times 4 \mathrm{NW}$ arrays. Fig. 2 shows the process flow for III-V 4D transistors. Novel process technologies in addition to those developed in [1] are highlighted in red. Fig. 3 shows the schematic diagram of the key steps in the fabrication process of III-V 4D transistors with 3 vertically stacked layers of InGaAs NWs.

The fabrication of III-V 4D transistors started with a 2 inch semi-insulating InP (100) substrate. The following layers were grown sequentially on the InP substrate: a $100 \mathrm{~nm}$ undoped InAlAs etch stop layer, an $80 \mathrm{~nm}$ undoped InP sacrificial layer, and then three layers of $30 \mathrm{~nm} \mathrm{In}_{0.53} \mathrm{Ga}_{0.47} \mathrm{As}$ channel with a $40 \mathrm{~nm}$ InP layer in between each channel layer (Fig. 3-1). To achieve uniform source/drain doping to contact each of the three vertically stacked channel layers, a two-step $\mathrm{Si}$ implantation was performed at an energy of $20 \mathrm{keV}$ and $60 \mathrm{keV}$ each with a dose of $1 \times 10^{14} \mathrm{~cm}^{-2}$. Rapid thermal annealing at $600^{\circ} \mathrm{C}$ for 15 seconds in $\mathrm{N}_{2}$ was carried out to activate the dopants (Fig. 3-2). To enable the formation of InGaAs/InP fins with a fin height $\left(\mathrm{H}_{\mathrm{Fin}}\right)$ of $200 \mathrm{~nm}$ via reactive ion etching, 10nm $\mathrm{ALD} \mathrm{Al}_{2} \mathrm{O}_{3}$ was deposited (Fig. 33) and patterned (Fig. 3-4) as a hard mask to replace the electron beam resist ${ }^{[1]}$, providing excellent etching selectivity and eliminating resist redeposition. A new $\mathrm{Cl}_{2} / \mathrm{O}_{2}$ fin etching process was developed replacing the $\mathrm{BCl}_{3}$ based etching ${ }^{[1]}$ to increase the etch rate and improve the sidewall quality (Fig. 3-5). HCl-based solution was used to release the NW arrays patterned along [100] direction (Fig. 3-6). The InAlAs etch stop layer provides a better control of the selective wet etching process. After $10 \%\left(\mathrm{NH}_{4}\right)_{2} \mathrm{~S}$ passivation, the sample was immediately loaded to the ALD reactor for $\mathrm{Al}_{2} \mathrm{O}_{3}$ and WN deposition at $300^{\circ} \mathrm{C}$ and $385^{\circ} \mathrm{C}$ respectively (Fig. 3-7). $\mathrm{CF}_{4} / \mathrm{O}_{2}$ based gate etch process was then performed, followed by the electron beam evaporation of $\mathrm{Au} / \mathrm{Ge} / \mathrm{Ni}$ and liftoff process to form the source/drain contacts (Fig. 3-8). After the formation of the source/drain alloy at $350^{\circ} \mathrm{C}, \mathrm{Cr} / \mathrm{Au}$ test pads were defined.

Fig. 4(a) shows a top-view SEM image of a III-V 4D transistor with 4 parallel NW stacks. Fig. 4(b) shows the fin structure after $\mathrm{Cl}_{2} / \mathrm{O}_{2}$ dry etching. The InGaAs channel layers, InP sacrificial layers and $\mathrm{Al}_{2} \mathrm{O}_{3}$ etch mask are highlighted. Fig. 4(c)-(d) show the high resolution cross sectional TEM images of InGaAs $3 \times 1$ and $3 \times 4 \mathrm{NW}$ arrays, showing that the ALD gate stack was coated around each nanowire. The $\mathrm{W}_{\mathrm{NW}}$ for layer 1, 2 and 3 is measured to be 20, 60 , and 100nm. A better anisotropic dry etch process needs to be developed to have uniform NWs vertically. The $\mathrm{H}_{\mathrm{NW}}$ for each layer is $30 \mathrm{~nm}$ defined by MBE. The ALD process of depositing highly conformal WN films for the gate metal is described in Ref [4]. The excellent step coverage of WN was examined on a sample of holes with $0.3 \mu \mathrm{m}$ in diameter and 
$11 \mu \mathrm{m}$ in depth (aspect ratio $=37: 1$ ). As shown in Fig. 5, the film thickness was $41 \mathrm{~nm}$ and $32 \mathrm{~nm}$ in the top and bottom zones, giving $78 \%$ step coverage on a structure with an aspect ratio of 37. A superior conformal ALD WN process is critical for the III-V 4D transistor process. All patterns were defined by a Vistec VB-6 UHR electron-beam lithography system. A Keithley 4200 was used to measure MOSFET output characteristics.

\section{Results and Discussion}

Fig. 6-8 show the well-behaved output characteristics, transfer characteristics, and $\mathrm{g}_{\mathrm{m}}-\mathrm{V}_{\mathrm{gs}}$ of a III-V 3D transistor (Sample 1) with $\mathrm{L}_{\mathrm{ch}}=50 \mathrm{~nm}$ and $\mathrm{W}_{\mathrm{NW}}=25 \mathrm{~nm}$. The current is normalized by the total perimeter of the $\mathrm{NW}$, i.e. $\mathrm{W}_{\mathrm{G}}=2 \times\left(\mathrm{W}_{\mathrm{NW}}+\mathrm{H}_{\mathrm{NW}}\right) \times($ Wire Number $)$. The $\mathrm{I}_{\mathrm{ON}}$ reaches $1.2 \mathrm{~mA} / \mu \mathrm{m}$ at $\mathrm{V}_{\mathrm{ds}}=1 \mathrm{~V}$ and $\mathrm{V}_{\mathrm{gs}}-\mathrm{V}_{\mathrm{T}}=1.2 \mathrm{~V}$, with maximum $\mathrm{g}_{\mathrm{m}}=1.1 \mathrm{mS} / \mu \mathrm{m}$ and $1.4 \mathrm{mS} / \mu \mathrm{m}$ at $\mathrm{V}_{\mathrm{ds}}=0.5 \mathrm{~V}$ and $1 \mathrm{~V}$ respectively. Good off-state performance is also achieved with $\mathrm{SS}=94 \mathrm{mV} / \mathrm{dec}$ and $\mathrm{DIBL}=50 \mathrm{mV} / \mathrm{V}$. Fig. 9-11 show the DIBL, SS and $\mathrm{V}_{\mathrm{T}}$ scaling metrics for Sample 1 compared with Sample 3 published in Ref. [1]. The $2 \times$ reduction in EOT greatly suppressed the short channel effects, evident by the dramatic reduction in DIBL, SS and the improvement in $\mathrm{V}_{\mathrm{T}}$ roll-off property. DIBL and SS are unchanged over the entire $\mathrm{L}_{\mathrm{ch}}$ range and show little dependence on $\mathrm{W}_{\mathrm{NW}}$, indicating an excellent electrostatic control on gate. No significant $\mathrm{V}_{\mathrm{T}}$ roll-off is observed for the $\mathrm{L}_{\mathrm{ch}}$ studied. Fig. 1213 show $\mathrm{I}_{\mathrm{on}}$ and $\mathrm{g}_{\mathrm{m}}$ scaling metrics for $\mathrm{W}_{\mathrm{NW}}=25,30$, and $35 \mathrm{~nm}$. Gradual increase in on-state metrics are obtained due to shorter $\mathrm{L}_{\mathrm{ch}}$. Higher $\mathrm{I}_{\mathrm{ON}}$ and $\mathrm{g}_{\mathrm{m}}$ are obtained on devices with smaller $\mathrm{W}_{\mathrm{NW}}$ due to the volume inversion effect ${ }^{[5]}$. Further scaling of $\mathrm{W}_{\mathrm{NW}}$ down to the sub-10nm regime may require new nanowire thinning techniques.

Fig. 14 shows the output characteristics of a $\mathrm{L}_{\mathrm{ch}}=200 \mathrm{~nm} 4 \mathrm{D}$ transistor with $3 \times 4 \mathrm{NW}$ array (Sample 2). The $\mathrm{I}_{\mathrm{ON}}$ reaches $1.35 \mathrm{~mA} / \mu \mathrm{m}$ at $\mathrm{V}_{\mathrm{ds}}=1 \mathrm{~V}$ and $\mathrm{V}_{\mathrm{gs}}=2 \mathrm{~V}$ normalized by perimeter. The device shows relatively large off-current, which is limited by the leakage current in the top nanowire layer due to the lack of optimization in our implantation process. Maximum $\mathrm{g}_{\mathrm{m}}$ of $0.6 \mathrm{mS} / \mu \mathrm{m}$ and $0.85 \mathrm{mS} / \mu \mathrm{m}$ are obtained at $\mathrm{V}_{\mathrm{ds}}=0.5 \mathrm{~V}$ and $1 \mathrm{~V}$ respectively, as shown in Fig. 15. The perimeter-normalized $\mathrm{I}_{\mathrm{ON}}$ and $\mathrm{g}_{\mathrm{m}}$ are comparable to those obtained from the best device of sample 3 with the same EOT. This indicates that the new $4 \mathrm{D}$ process technology can provide high quality InGaAs NW despite more complicated fabrication. The source/drain resistance $\left(\mathrm{R}_{\mathrm{SD}}\right)$ is extracted to be $\sim 600 \Omega \cdot \mu \mathrm{m}$, which can be improved by optimizing the implantation process. Fig. 16 shows the gate leakage current for sample 1, 2, and 3. Sample 2 (4D) shows similarly low gate leakage as Sample 3 (3D), while Sample 1 (3D) shows a slightly increased leakage at a large gate voltage due to the reduction of EOT. Further EOT scaling on both 3D and 4D structures is achievable. Fig. 17 depicts $\mathrm{g}_{\mathrm{m}}-\mathrm{V}_{\mathrm{gs}}$ for III-V 4D transistors with $3 \times 2$ versus $3 \times 4$ NW arrays, showing increased drivability, e.g. $\mathrm{I}_{\mathrm{ON}}$, by adding NW stacks. To benchmark the overall current drivability for $3 \mathrm{D}$ and $4 \mathrm{D}$ technologies, $\mathrm{I}_{\mathrm{ON}}$ and $\mathrm{g}_{\mathrm{m}, \max }$ are normalized by $\mathrm{W}_{\text {pitch }}$, defined as the maximum $\mathrm{W}_{\mathrm{NW}}$ of the vertical NW stacks. For III-V $3 \mathrm{D}$ transistors, $\mathrm{W}_{\text {pitch }}=\mathrm{W}_{\mathrm{NW}}$. The $\mathrm{I}_{\mathrm{ON}} / \mathrm{W}_{\text {pitch }}$ and $\mathrm{g}_{\mathrm{m}} / \mathrm{W}_{\text {pitch }}$ are figures of merit which evaluate the drivability per unit width along the plane of the wafer, as shown in Figs. 18-19. Sample 1 shows $2 \times \mathrm{I}_{\mathrm{ON}}$ and $2.5 \times \mathrm{g}_{\mathrm{m}}$ enhancement over Sample 3 due to mobility enhancement and EOT scaling. Sample 2 shows additional $2 \times \mathrm{I}_{\mathrm{ON}}$ and $1.5 \times \mathrm{g}_{\mathrm{m}}$ enhancement over Sample 1 due to the introduction of $4 \mathrm{D}$ structure despite its larger EOT. Maximum $\mathrm{I}_{\mathrm{ON}} / \mathrm{W}_{\text {pitch }}$ and $\mathrm{g}_{\mathrm{m}} / \mathrm{W}_{\text {pitch }}$ reaches $9 \mathrm{~mA} / \mu \mathrm{m}$ and $6.2 \mathrm{mS} / \mu \mathrm{m}$ for $4 \mathrm{D}$ FETs, which can be further improved by reducing the EOT and $\mathrm{R}_{\mathrm{SD}}{ }^{[6-9]}$.

\section{Conclusion}

We have experimentally demonstrated, for the first time, the fabrication process of III-V 4D transistors using ALD high$\mathrm{k} / \mathrm{metal}$ gate stacks. Electrostatic control has been improved by $2 \times$ EOT scaling. Record high $\mathrm{I}_{\mathrm{ON}} / \mathrm{W}_{\text {pitch }}$ and $\mathrm{g}_{\mathrm{m}} / \mathrm{W}_{\text {pitch }}$ of $9 \mathrm{~mA} / \mu \mathrm{m}$ and $6.2 \mathrm{mS} / \mu \mathrm{m}$ has been obtained for the III-V $4 \mathrm{D}$ transistors, showing $4 \times$ improvement over the III-V 3D transistors. The III-V 4D transistor structure is very promising for future high-speed low-power logic and RF applications.

\section{Acknowledgement}

The authors would like to thank X. L. Li, M. S. Lundstrom, D. A. Antoniadis, and J. A. del Alamo for the valuable discussions. This work is supported by the SRC FCRP MSD Center, NSF and AFOSR.

\section{References}

[1] J. J. Gu et. al., "First Experimental Demonstration of Gate-all-around IIIV MOSFETs by Top-down Approach”, IEDM Tech. Dig. 769 (2011).

[2] L. K. Bera et. al., "Three Dimensionally Stacked SiGe Nanowire Array and Gate-All-Around p-MOSFETs", IEDM Tech. Dig. 1 (2006).

[3] W. W. Fang et. al., "Vertically stacked SiGe nanowire array channel CMOS transistors", IEEE Electron Device Lett., 28, 221 (2007).

[4] J. S. Becker et al., "Highly Conformal Thin Films of Tungsten Nitride Prepared by Atomic Layer Deposition from a Novel Precursor", Chem. Mater. 15, 2969 (2003).

[5] J. J. Gu et. al., "Size-dependent-transport Study of $\mathrm{In}_{0.53} \mathrm{Ga}_{0.47}$ As Gate-allaround Nanowire MOSFETs: Impact of Quantum Confinement and Volume Inversion", IEEE Electron Device Lett. 33, 967 (2012).

[6] M. Radosavljevic et al., "Electrostatics Improvement in 3-D Tri-gate Over Ultra-Thin Body Planar InGaAs Quantum Well Field Effect Transistors with High-K Gate Dielectric and Scaled Gate-to-Drain/Gateto-Source Separation", IEDM Tech. Dig. 765 (2011).

[7] M. Egard et al., "High Transconductance Self-Aligned Gate-Last Surface Channel $\mathrm{In}_{0.53} \mathrm{Ga}_{0.47}$ As MOSFET", IEDM Tech. Dig. 303 (2011).

[8] X. Zhang et al., "Multiple-Gate $\mathrm{In}_{0 .}{ }_{53} \mathrm{Ga}_{0 .}{ }_{47} \mathrm{As}$ Channel n-MOSFETs with Self-Aligned Ni-InGaAs Contacts", ECS Trans.45, 209 (2012).

[9] S. Kim et. al., "Sub-60 nm Deeply-Scaled Channel Length Extremelythin Body $\mathrm{In}_{\mathrm{x}} \mathrm{Ga}_{1-\mathrm{x}}$ As-On-Insulator MOSFETs on Si with Ni-InGaAs Metal S/D and MOS Interface Buffer Engineering", VLSI Tech. Dig. 177 (2012). 

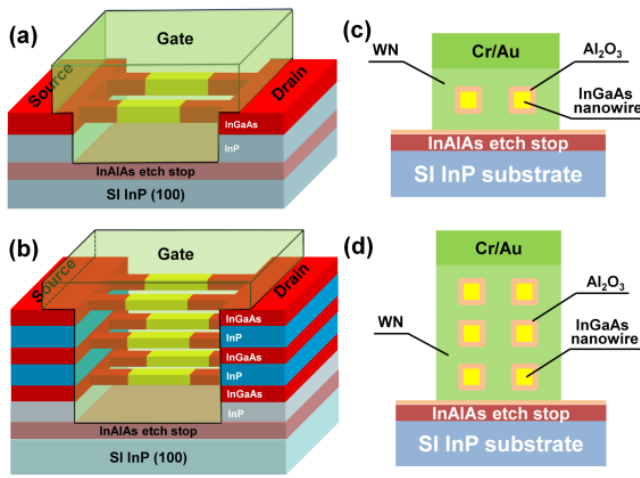

Fig. 1 Schematic diagram of III-V (a) 3D and (b) 4D transistors. (c) and (d) show the cross sectional views of the NWs for (a) and (b), showing $1 \times 2$ and $3 \times 2 \mathrm{NW}$ arrays, respectively.
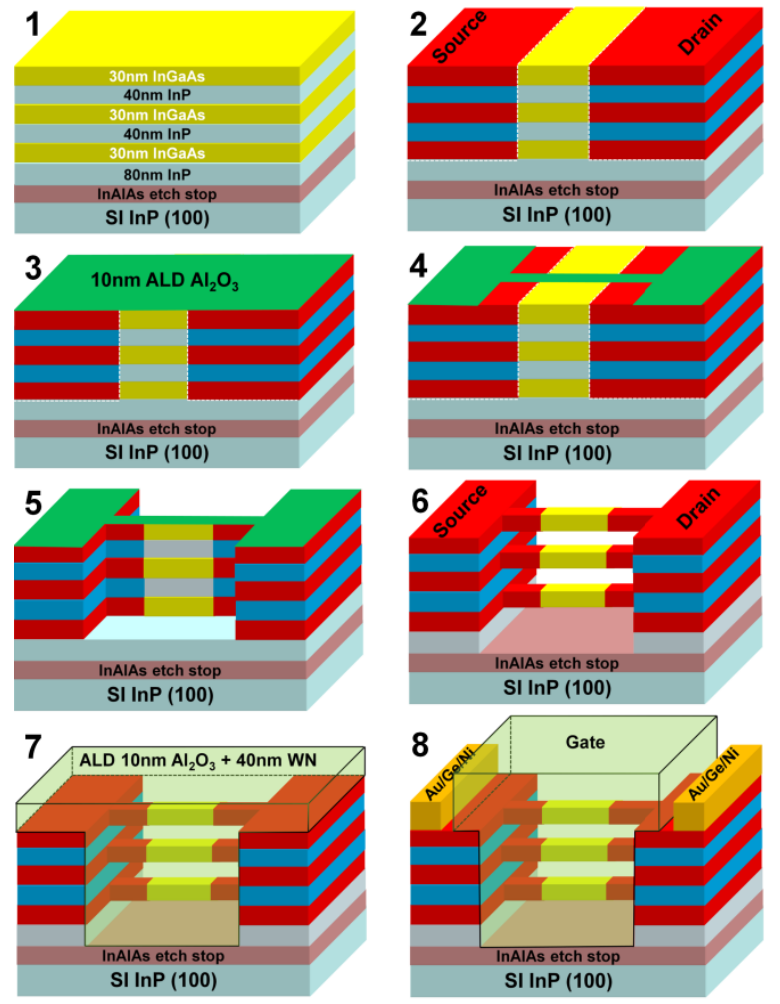

Fig. 3 Schematic diagram of the key process steps in the fabrication of III-V 4D transistors with 3 layers of InGaAs NWs stacked vertically.

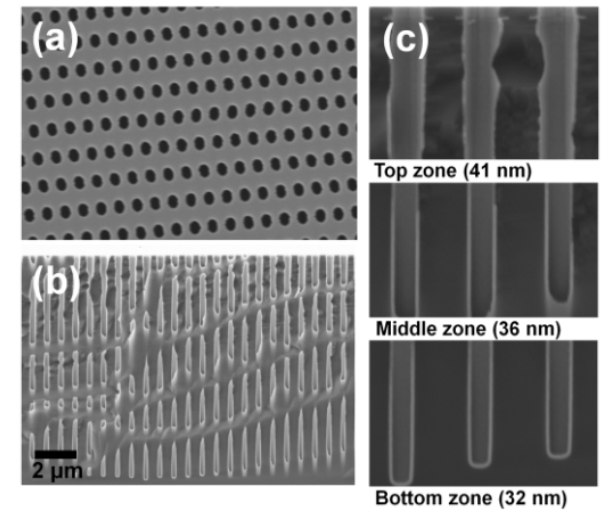

Fig. 5 (a) Top-view and (b)-(c) cross sectional SEM images of an ALD WN coated hole sample with an aspect ratio of $37: 1$. The film thickness of $41 \mathrm{~nm}, 36 \mathrm{~nm}$, and $32 \mathrm{~nm}$ was obtained in top, middle and bottom zones, indicating $78 \%$ step coverage.
MBE growth
$\mathrm{S} / \mathrm{D}$ implantation $\left(\mathrm{Si}, 20 \mathrm{keV}+60 \mathrm{keV}, 1 \times 10^{14} \mathrm{~cm}^{-2}\right)$

Dopant activation $\left(600^{\circ} \mathrm{C} 15 \mathrm{sec}\right.$ in $\left.\mathrm{N}_{2}\right)$

ALD $10 \mathrm{~nm} \mathrm{Al}_{2} \mathrm{O}_{3}$ deposition as hard mask

Fin ICP etch $\left(\mathrm{Cl}_{2} / \mathrm{O}_{2}\right)$

$\mathrm{HCl}: \mathrm{H}_{2} \mathrm{O}(1: 2)$ nanowire release

$10 \%\left(\mathrm{NH}_{4}\right)_{2} \mathrm{~S} 20 \mathrm{~min}$ passivation

ALD high-k dielectric deposition (10nm $\mathrm{Al}_{2} \mathrm{O}_{3}$ )

ALD metal gate deposition (WN 40nm)

Cr/Au gate definition

WN gate etch $\left(\mathrm{CF}_{4} / \mathrm{Ar}\right)$

Au/Ge/Ni S/D

Pad definition

Table $1 \mathrm{NW}$ array (vertical $\times$ lateral), NW size and EOT splits for Samples 1 and 2 fabricated in this work, and Sample 3 in Ref. [1].

\begin{tabular}{|c|c|c|c|c|c|c|}
\hline & Structure & \begin{tabular}{|c|} 
Nanowire \\
Array \\
$(H \times W)$
\end{tabular} & $\begin{array}{c}\mathrm{Al}_{2} \mathrm{O}_{3} \\
\text { Thickness } \\
(\mathrm{nm})\end{array}$ & $\begin{array}{l}\mathrm{W}_{\mathrm{NW}} \\
(\mathrm{nm})\end{array}$ & $\begin{array}{l}\mathrm{H}_{\mathrm{NW}} \\
(\mathrm{nm})\end{array}$ & $\underset{(x)}{\ln _{x} G_{1-x} A s}$ \\
\hline \multirow{3}{*}{$\begin{array}{c}\text { Sample } 1 \\
\text { (This } \\
\text { work) }\end{array}$} & \multirow{3}{*}{ 3D } & \multirow{3}{*}{$1 \times 4$} & \multirow{3}{*}{5} & 25 & \multirow{3}{*}{30} & \multirow{3}{*}{$65 \%$} \\
\hline & & & & 30 & & \\
\hline & & & & 35 & & \\
\hline \multirow{2}{*}{$\begin{array}{c}\text { Sample 2 } \\
\text { (This } \\
\text { work) }\end{array}$} & \multirow{2}{*}{ 4D } & $3 \times 2$ & \multirow{2}{*}{10} & 20 (Layer1) & \multirow{2}{*}{30} & \multirow{2}{*}{$53 \%$} \\
\hline & & $3 \times 4$ & & $\begin{array}{l}60 \text { (Layer2) } \\
100 \text { (Layer3) }\end{array}$ & & \\
\hline \multirow{4}{*}{$\begin{array}{l}\text { Sample 3 } \\
\text { (IEDM11) }\end{array}$} & \multirow{4}{*}{$3 D$} & $1 \times 1$ & \multirow{4}{*}{10} & 30 & \multirow{4}{*}{30} & \multirow{4}{*}{$53 \%$} \\
\hline & & $1 \times 4$ & & & & \\
\hline & & $1 \times 9$ & & 50 & & \\
\hline & & $1 \times 19$ & & & & \\
\hline
\end{tabular}

Fig. 2 Fabrication process flow for the III-V 4D transistors with vertical and lateral integrations of InGaAs NWs. Novel process technologies in ddition to those developed in Ref. [1] are highlighted in red. (a)

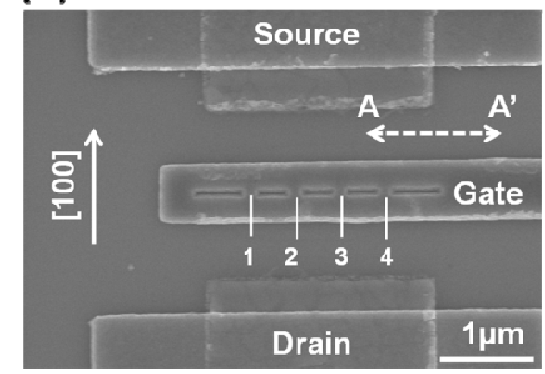

(c)

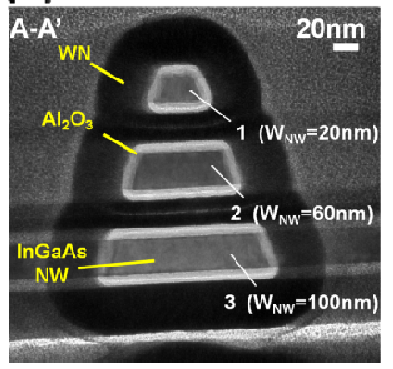

(d) (b)
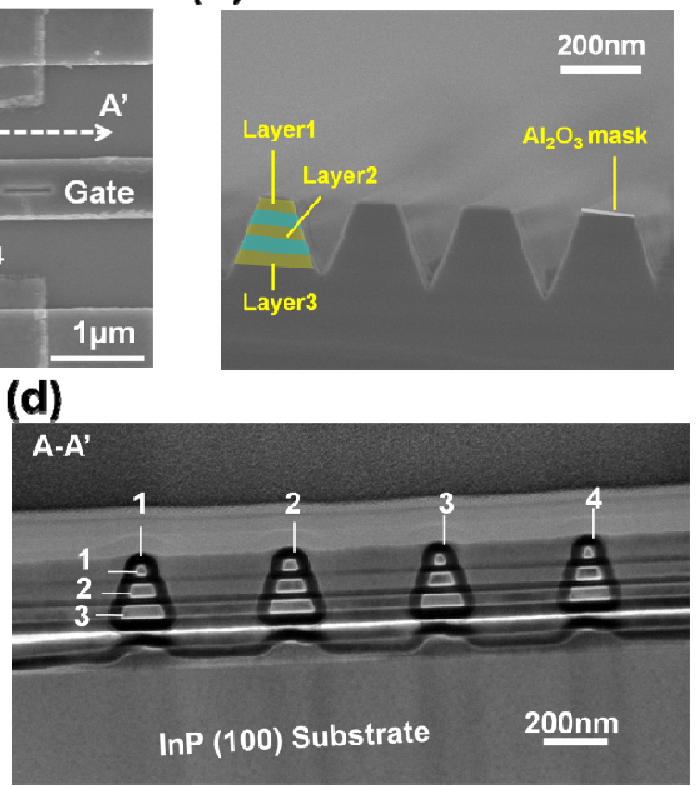

Fig. 4 (a) Top-view SEM image of a III-V 4D transistor with 4 parallel NW stacks. (b) Cross-sectional SEM image of a InGaAs/InP fin test structure fabricated by $\mathrm{Cl}_{2} / \mathrm{O}_{2}$ dry etching with $\mathrm{ALD} \mathrm{Al}_{2} \mathrm{O}_{3}$ as a hard mask (c) Cross-sectional TEM image of a $3 \times 1$ InGaAs NW stack. The $\mathrm{W}_{\mathrm{NW}}$ for layer 1,2 and 3 is measured to be 20,60 , and $100 \mathrm{~nm}$. A better anisotropic dry etch process needs to be developed. The $\mathrm{H}_{\mathrm{NW}}$ for each layer is $30 \mathrm{~nm}$ defined by MBE. (d) Cross-sectional TEM image of a $3 \times 4 \mathrm{NW}$ array on a real device.

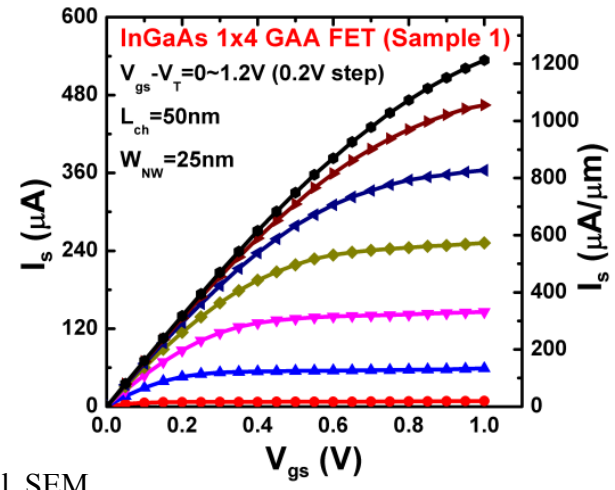

Fig. 6 Output characteristics of a III-V $3 \mathrm{D}$ FET with $1 \times 4 \mathrm{NW}$ array (Sample 1 ). Current is normalized by the total perimeter of the NWs.

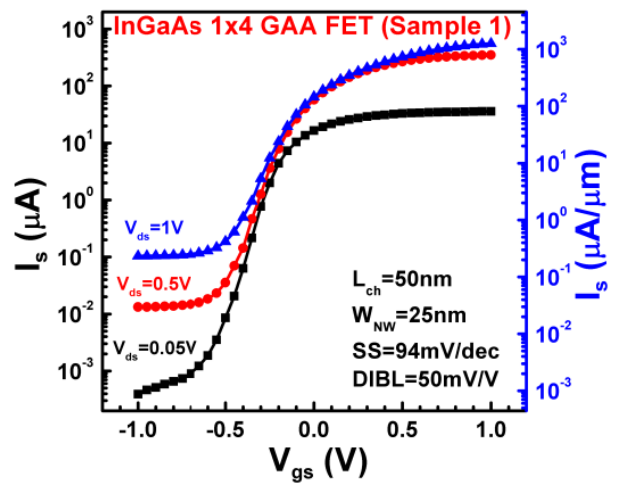

Fig. 7 Transfer characteristics of a III-V 3D FET with $1 \times 4 \mathrm{NW}$ array (Sample 1). 

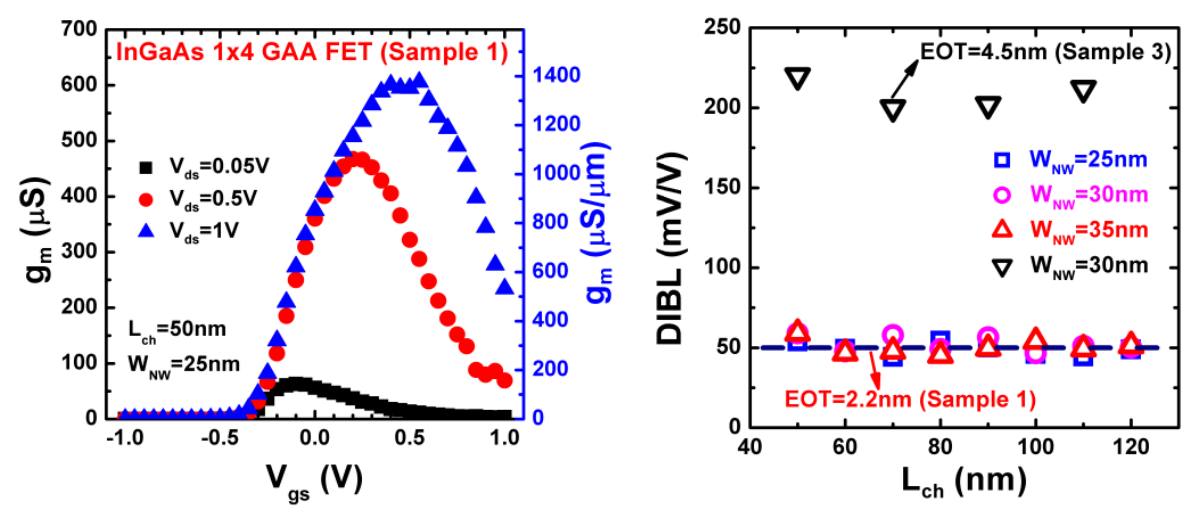

Fig. $8 \mathrm{~g}_{\mathrm{m}}-\mathrm{V}_{\mathrm{gs}}$ of a III-V 3D FET with $1 \times 4 \mathrm{NW}$ array (Sample 1).

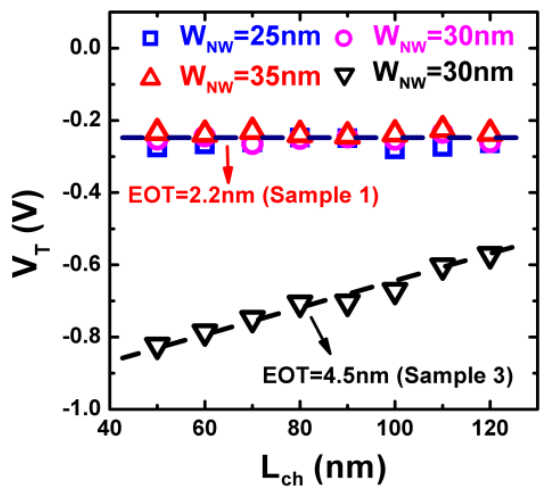

Fig. $11 \mathrm{~V}_{\mathrm{T}}$ scaling metrics for a III-V 3D FET with $1 \times 4$ NW array (Sample 1) compared with Sample 3 in Ref. [1]

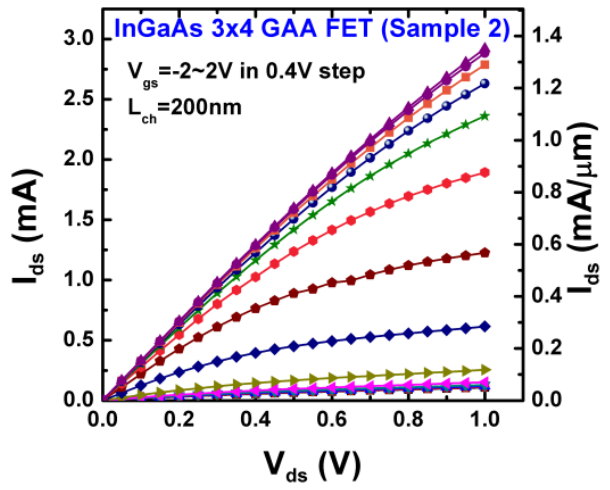

Fig. 14 Output characteristics of a III-V 4D FET with $3 \times 4 \mathrm{NW}$ array (Sample 2).

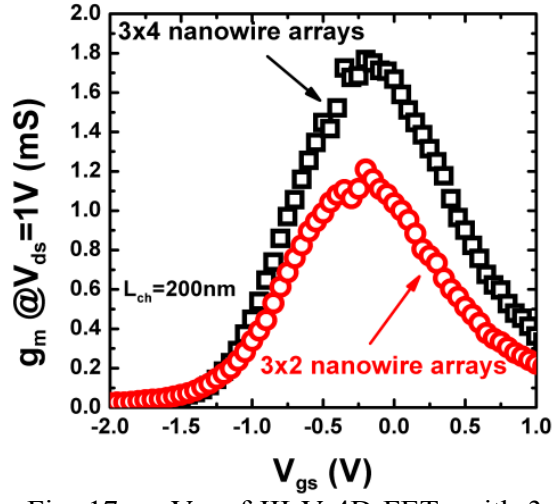

Fig. $17 \mathrm{~g}_{\mathrm{m}}-\mathrm{V}_{\mathrm{gs}}$ of III-V 4D FETs with $3 \times 2$ and $3 \times 4$ NW arrays. The $2 \times$ increase in NW number results in $\sim 1.5 \times$ increase in maximum $\mathrm{g}_{\mathrm{m}}$ due to the variation in NW size, which can be improved by optimizing the fabrication process.
Fig. 9 DIBL scaling metrics for a III-V 3D FET with $1 \times 4$ NW array (Sample 1) compared with Sample 3 in Ref. [1].

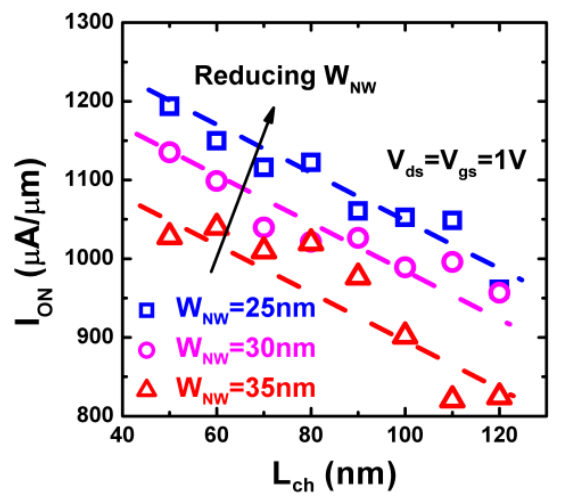

Fig. $12 \mathrm{I}_{\mathrm{ON}}$ scaling metrics for III-V 3D FETs with $1 \times 4$ NW arrays (Sample 1), showing increased $\mathrm{I}_{\mathrm{ON}}$ with a reduced $\mathrm{W}_{\mathrm{NW}}$.

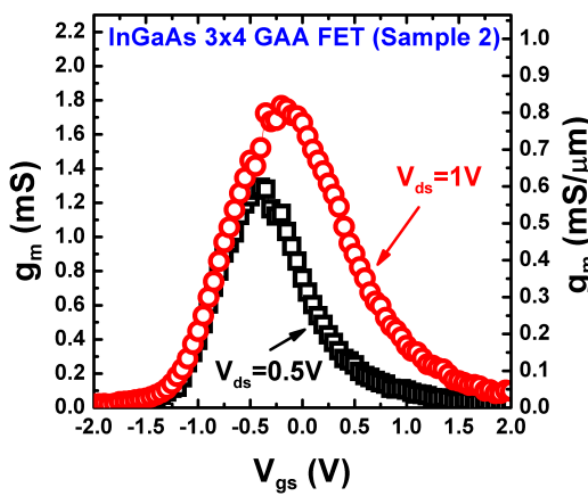

Fig. $15 \mathrm{~g}_{\mathrm{m}}-\mathrm{V}_{\mathrm{gs}}$ of a III-V 4D FET with $3 \times 4 \mathrm{NW}$ array (Sample 2).

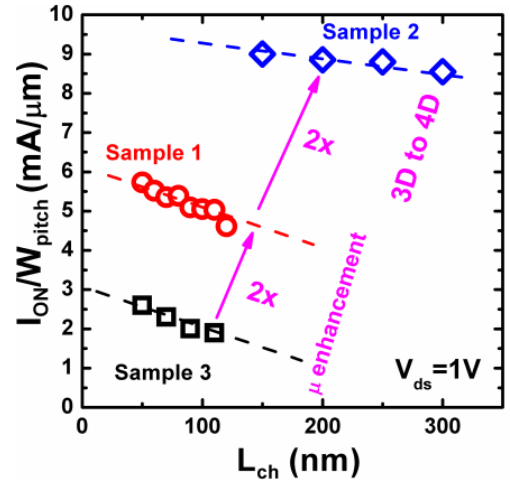

Fig. 18 Benchmarking $\mathrm{I}_{\mathrm{ON}}$ per $\mathrm{W}_{\text {pitch }}$ for Samples 1, 2, and 3, indicating the benefit of EOT scaling, mobility enhancement and vertical NW stacking from $3 \mathrm{D}$ to $4 \mathrm{D}$ integration.

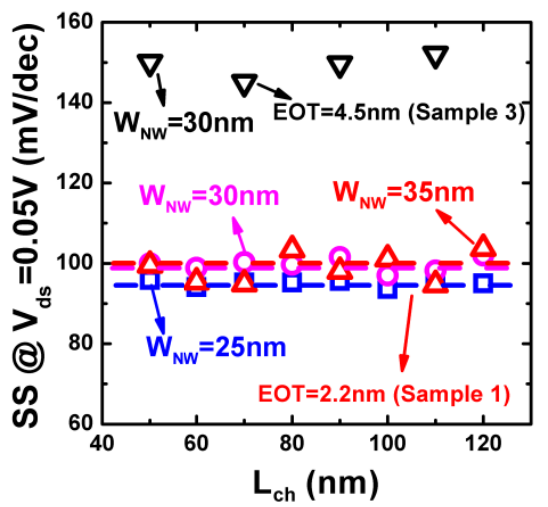

Fig. 10 SS scaling metrics for a III-V 3D FET with $1 \times 4$ NW array (Sample 1) compared with Sample 3 in Ref. [1].

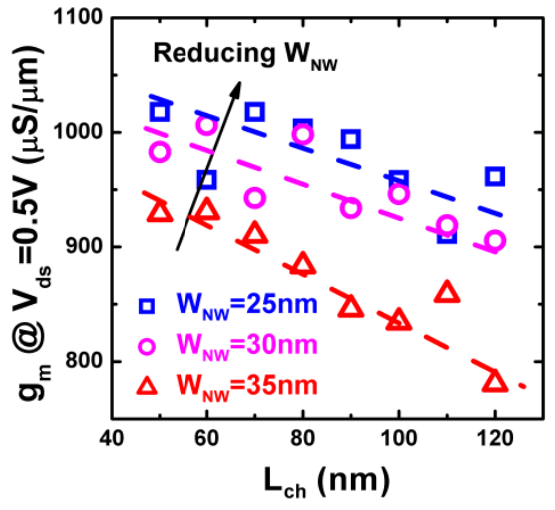

Fig. $13 \mathrm{~g}_{\mathrm{m}}$ scaling metrics for III-V 3D FETs with $1 \times 4 \mathrm{NW}$ arrays (Sample 1), showing increased $g_{m}$ with reduced $W_{N W}$.

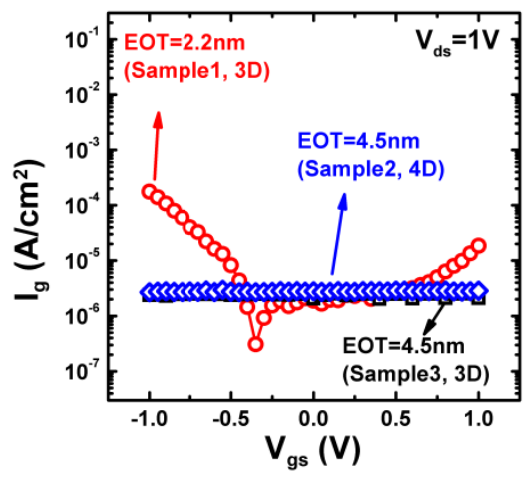

Fig. 16 Gate leakage current density for III-V 3D and 4D FETs (Samples 1, 2, and 3).

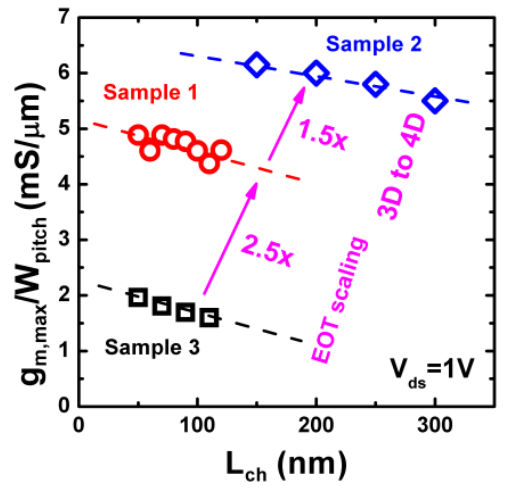

Fig. 19 Benchmarking $g_{m}$ per $\mathrm{W}_{\text {pitch }}$ for Samples 1, 2, and 3, indicating the benefit of EOT scaling, mobility enhancement and vertical NW stacking from $3 \mathrm{D}$ to $4 \mathrm{D}$ integration. 